\title{
A Study into Listening Comprehension Strategies by Effective and Ineffective Listeners in Simultaneous Typing
}

\author{
Li Zhou*, Beilei Chen and Yongwei Nie
}

Foreign Language School, Wuchang Institute of Technology, Wuhan, 430065, China

\begin{abstract}
This article attempts to make clear how listening comprehension strategies (LCSs) influence listening performance in simultaneous typing. The article firstly reviewed the background of the study, secondly introduced a study into LCSs from the aspect of the research procedure, and finally gave some suggestions based on the results and analysis of study.
\end{abstract}

Keywords: Effective and ineffective listeners, listening comprehension strategies, simultaneous typing.

\section{THE BACKGRUND OF THE RESEACH}

\subsection{Definition of Listening Comprehension Strategies}

LCSc can be regarded as one aspect of learning strategies, for researchers have designed its basic framwork by learning strategies. According to O'Malley, a brief definition of learning strategies is "the special thought and behaviors that individuals use to help them comprehend, or retain new information." Vandergrift [1] believes that listening plays the most important role in the primary stage of language learning. Perkins [2] stated that listening is very active and integrative language skill, involving a grasp of phonological, lexical, grammatical, and ideological complexities as well as performance factors.

LCSs in this study refers to techniques to process information that enhance listening comprehension, or retention of the information, which are used by the second language learner while listen to English materials.

\subsection{Theoretical Background of LCSs}

From 1990s, listening strategy began to become the top concern of the researchers, a large number of foreign researches on learning strategy emerged [3]. Since then, the learning strategies of language learners have been researched extensively [4]. The researches proved that students' brain activity was composed of three stages during listening: perception, analysis and practice. They also found that, the learners had a tendency to the choices of strategies in the three different stages [5]. Although there are several learning strategies modes in improving the consciousness and usage of strategies in the strategy training process, we can say that there is not an all-round way recognized as the best [6]. Strictly speaking, the strategy is complementary. With the improvement of listeners, less and less strategies are used.
One's listening proficiency is affected by his fluency and listening skills. Language proficiency may not improve in the short term, but teachers can rapidly improve the students' listening skills in the classroom to teach listening strategies [7].

Listening has been assumed a central role in language learning with the occurrence of some learning theories such as the well-known input hypothesis and comprehension input of Krashen (1985). To listening process, which are often considered "black box", nowadays, researchers have begun to recognize that they are not only a simple decoding process but also a process of combination between decoding process and meaning structure. Thus, the researches of LCSs have begun to arouse the attention of both language researchers and teachers.

The importance of meta-cognition in foreign language learning has been widely recognized. Metacognition is defined as "cognition beyond cognition" [8], refers to the individual's understanding and control of the cognitive process. Research has shown that, metacognitive awareness and listening strategies play important roles in the process of listening comprehension [9].

In our country, the study of English learning strategies is from the beginning of the mid- $80 \mathrm{~s}$, but the amount is not enough, and the research involves a wide enough. Most of the research carried out is on the investigation of theories and the introduction of the questionnaire. Studies on listening practice are limited. Related articles published in major journals of Chinese scholars at home and abroad are only seven [10].

However, there are a limited number of researches in China (see Table 1). It is true that a large number of university students in China who, after 7 or 8 years of English study, cannot perform well in listening comprehension. Thus it is valuable to carry out some researches to probe the certain efficient listening strategies used by some students in China. 
Table 1. The statistics on the research subject of listening strategies.

\begin{tabular}{|c|c|c|}
\hline Research Subject & $\begin{array}{c}\text { The Number of } \\
\text { the Research } \\
\text { Paper }\end{array}$ & $\begin{array}{c}\text { The Proportion of } \\
\text { the Whole Re- } \\
\text { search Paper }\end{array}$ \\
\hline \hline Postgraduates & 1 & 2.2 \\
\hline $\begin{array}{c}\text { Undergraduates (non- } \\
\text { English majors) }\end{array}$ & 23 & 50.0 \\
\hline $\begin{array}{c}\text { Undergraduates (English } \\
\text { majors) }\end{array}$ & 19 & 41.3 \\
\hline $\begin{array}{c}\text { Higher Vocational College } \\
\text { Students }\end{array}$ & 2 & 4.3 \\
\hline Middle school students & 0 & 2.2 \\
\hline Pupils & 1 & 0 \\
\hline
\end{tabular}

\section{A RESEARCH INTO LCSS}

\subsection{Research Purpose}

This research aims to find out what are the strategies most used by the students, what are the differences between effective and ineffective listeners. Thus the results of the research can convey the certain efficient listening strategies used by effective listeners to some ineffective ones.

\subsection{Research Questions}

(1) What are the listening strategies that effective and ineffective listeners in simultaneous typing most frequently use respectively?

(2) What are the similarities and differences between effective and ineffective listeners in simultaneous typing?

\subsection{Subjects}

The participants come from Wuchang Institute of Technology. They are undergraduates major in English in their second-year study. Of them 15 males make up $65 \%$ and 28 females make up $35 \%$. The average age of the subjects 21 and they have learnt English for 8 years. They are taught by the same teacher in the course of simultaneous typing.

In order to improve their typing speed, the students are divided into three groups by the range of their final examination scores and scores in listening part in the final examination. Among them, the top 15 are categorized as group1, that is the effective group, while the last 15 students as group 2, that is the ineffective group, and the rest are considered as medium. This study will mainly concern the group 1 and group 2 .

\subsection{Instrument}

The instrument is a questionnaire. And the questionnaire is divided into two parts.

\section{Part A: Personal Details}

In this part, the subjects are asked to tell their name, gender, the scores of the final examination and scores of the listening comprehension part. It is true that the effective lis- teners who score over 15 points (20 in total) perform also well in their terms tests.

\section{Part B: Questionnaire}

This part contains 28 statements concerning LCSs, each have 5 scales, ranking from never/ seldom/ sometimes/ often/ always. And these 28 statements are divided into three parts according to O'Malley and Chamot (2001) (Table 2). That Metacognitive strategies involve planning and thinking about learning, Cognitive strategies involve conscious ways of tackling learning and Affective/Social strategies include a broad grouping that involves either interaction with another person or ideational control over effect.

\subsection{Data Collection}

The results of theses questionnaires were arranged into $1 / 2 / 3 / 4 / 5$. $(1=$ never, $2=$ seldom, $3=$ sometimes, $4=$ often, $5=$ always) The mean value was used. All of the questionnaires were collected, group1 and group2's questionnaires were analyzed.

\begin{tabular}{|c|c|}
\hline Mean & The Frequency of the Use of the Strategy \\
\hline \hline $1.0-1.4$ & never use this strategy \\
\hline $1.5-2.4$ & seldom use this strategy \\
\hline $2.5-3.4$ & sometimes use this strategy \\
\hline $3.5-5.0$ & often use this strategy \\
\hline
\end{tabular}

The questionnaire is a five-point scale, therefore, according to the Oxford's method, the number of mean of each strategy infers the frequency of this strategy. The detailed relationship is as follows (Oxford, 2000) .

The higher he mean score is, the more often the strategy is used before conducting data analysis, the author shall firstly test the feasibility of the questionnaire by measuring the internal consistency of listening strategies. Cronbach Alpha: this is a measurement of internal consistency of the items of the questionnaire. The higher the correlation among the items, the greater the value of alpha. Alpha can vary from 0 to 1 , indicationg that the questionnaire is perfectly reliabel, Generlly speaking, the questions are recognized internally well-consistent if alpha is over 0.70 . In this research, the author will identity whether the questions on listening strategies are internally consistent according to alpha.

The three Tables 3-5 above show that the Alpha values of the three categories are respectively $0.737>0.7,0.848>0.7$, $0.711>0.7$. Statistics show if the Alpha number is larger than 0.7 , the three items are closely correlated and the relationship among these strategies can be further tested. For the three types of listening strategies, there exits close correlations between each specific strategy and each major type it belongs. Therefore, it provides the evidence that the questions are logically related and reasonable and the questionnaire holds ground and viability.

\section{RESULTS AND DISCUSSIONS}

The following Table 6 is the statistic results of each listening strategy by two groups of listeners. 
Table 2. The 28 statements of the questionnaire.

\section{Metacognitive Strategies}

1.I have defined goals and plans. $(1,2,3,4,5)$

2.I have good evaluation and proper recognition to my own listening ability. $(1,2,3,4,5)$

3.I keep trying to search for some listening materials suit or a little bit beyond my level to practice. $(1,2,3,4,5)$

4.I have a look at the answers then do listening. $(1,2,3,4,5)$

5.I can focus myself on the content I'm listening for a long period. $(1,2,3,4,5)$

6.While listening to English,the noise and environment surrounds me influence the content I'm listening to. $(1,2,3,4,5)$

7.When my mind wanders around, I can realize it and force my attention on the material quickly. $(1,2,3,4,5)$

8.I usually do some excises to promote listening after classes, including the acquaintance and command of standard pronunciation or intonation. (1, 2, 3, 4, 5)

9.I try to find out the reasons of ineffective listening. $(1,2,3,4,5)$

\section{Cognitive Strategies}

10.When listening to English materials,I correct the pronunciation firstly and figure out the meaning of words. $(1,2,3,4,5)$

11.During the process of listening,I try to understand meanings of every word and sentence, in other words,from pronunciation to words, then to sentences. $(1,2,3,4,5)$

12.If I meet new words while listening,I would ignore them and continue my listening. $(1,2,3,4,5)$

13. I guess the word I heard by its context $(1,2,3,4,5)$

14.If I meet new words while listening, I will memorize word's pronunciation as possible as I can, then consult the dictionary for its spelling and meaning. $(1,2,3,4,5)$

15.I translate the content in the meantime I listen to English. $(1,2,3,4,5)$

16.During the process of listening,I image the content I have listened to,and turn it into scenes. $(1,2,3,4,5)$

17.I use different methods for listening toward different topics. $(1,2,3,4,5)$

18.I try to remember what I heard in English. $(1,2,3,4,5)$

19.I try to retell what I heard with my own words. $(1,2,3,4,5)$

20.I summarize the contents if necessary. $(1,2,3,4,5)$

21.I write down notes while listening, such as characters, time and place. $(1,2,3,4,5)$

22.I do bold guesses on the context and associate them with the known knowledge according to the question. $(1,2,3,4,5)$

23.I will listen what confuses me during the class repeatedly, and summarize the reasons why I could not understand it at that time. $(1,2,3,4,5)$

24.I can use cutural background knowledge to promot my listening ability. $(1,2,3,4,5)$

\section{Affective/Social strategies}

25.Try to enlarge my knowledge and know cultural backgrounds and customs of some English countries. $(1,2,3,4,5)$

26.I tend to communicate with my teachers and classmates, exchanging some effective methods to promote listening. $(1,2,3,4,5)$

27.I give myself a reward when I fulfill a listening. $(1,2,3,4,5)$

28.If I feel stressful ,I will take a deep breath or use other methods to relax myself. $(1,2,3,4,5)$

Table 3. Reliability statistics of cognitive strategies.

\begin{tabular}{|c|c|c|}
\hline Cronbach's Alpha & $\begin{array}{c}\text { Cronbach's Alpha Based } \\
\text { on Standardized Items }\end{array}$ & N of Item \\
\hline \hline .737 & .734 & 15 \\
\hline
\end{tabular}

Table 4. Reliability statistics of metacognitive strategies.

\begin{tabular}{|c|c|c|}
\hline Cronbach's Alpha & $\begin{array}{c}\text { Cronbach's Alpha Based } \\
\text { on Standardized Items }\end{array}$ & N of Item \\
\hline \hline .848 & .853 & 9 \\
\hline
\end{tabular}


Table 5. Reliability statistics of affective/social strategies.

\begin{tabular}{|c|c|c|}
\hline Cronbach's Alpha & $\begin{array}{c}\text { Cronbach's Alpha Based } \\
\text { on Standardized Items }\end{array}$ & N of Item \\
\hline \hline .711 & .717 & 4 \\
\hline
\end{tabular}

\subsection{The Listening Strategies that Effective Listeners in Simultaneous Typing Most Frequently Use}

The most frequently used here means the choice of 4 or 5. Table 7 rank order shows the statistic results. The strategy used most by students is ranked number 1 in the table; the second most used in number 2 , and so on that is showed in the RN column. The strategy number in the designed questionnaire is in the strategy number column. Further, Mean column displays the mean value of the ranked strategy among 28 strategies chosen by the 30 subjects. In the Mean column, those strategies whose mean value is over 3 are displayed. Because all of the strategies displayed in Tables 1-4 are used by the subjects with high frequency (based on the standard of 5-point Liken-scale). The last column ST indicates the strategy type of the aforementioned ranked strategies that is classification of O'Malley and Chamot (2001)

Table 6. The statistic results of the use of each listening strategy by two groups.

\begin{tabular}{|c|c|c|c|c|c|c|c|}
\hline Strategies & Groups & Category & Mean & Strategies & Groups & Category & Mean \\
\hline \multirow{2}{*}{ stra1 } & Group1 & Effective & 3.19 & \multirow{2}{*}{ stra 15} & Group1 & Effective & 2.99 \\
\hline & Group2 & Ineffective & 2.82 & & Group2 & Ineffective & 3.13 \\
\hline \multirow{2}{*}{ stra2 } & Group1 & Effective & 2,98 & \multirow{2}{*}{ stra 16} & Group1 & Effective & 3.14 \\
\hline & Group2 & Ineffective & 2.64 & & Group2 & Ineffective & 2.75 \\
\hline \multirow{2}{*}{ stra3 } & Group1 & Effective & 2.96 & \multirow{2}{*}{ stra17 } & Group1 & Effective & 2.99 \\
\hline & Group2 & Ineffective & 2.70 & & Group2 & Ineffective & 2.65 \\
\hline \multirow{2}{*}{ stra4 } & Group1 & Effective & 3.15 & \multirow{2}{*}{ stra 18} & Group1 & Effective & 2.70 \\
\hline & Group2 & Ineffective & 2.71 & & Group2 & Ineffective & 3.06 \\
\hline \multirow{2}{*}{ stra5 } & Group1 & Effective & 2.96 & \multirow{2}{*}{ stra19 } & Group1 & Effective & 3.11 \\
\hline & Group2 & Ineffective & 2.78 & & Group2 & Ineffective & 3.11 \\
\hline \multirow{2}{*}{ stra6 } & Group1 & Effective & 2.81 & \multirow{2}{*}{ stra20 } & Group1 & Effective & 2.74 \\
\hline & Group2 & Ineffective & 2.76 & & Group2 & Ineffective & 2.55 \\
\hline \multirow{2}{*}{ stra7 } & Group1 & Effective & 2.83 & \multirow{2}{*}{ stra21 } & Group1 & Effective & 2.62 \\
\hline & Group2 & Ineffective & 2.81 & & Group2 & Ineffective & 2.53 \\
\hline \multirow{2}{*}{ stra8 } & Group1 & Effective & 2.92 & \multirow{2}{*}{ stra22 } & Group1 & Effective & 3.15 \\
\hline & Group2 & Ineffective & 2.77 & & Group2 & Ineffective & 2.84 \\
\hline \multirow{2}{*}{ stra9 } & Group1 & Effective & 3.18 & \multirow{2}{*}{ stra23 } & Group1 & Effective & 2.68 \\
\hline & Group2 & Ineffective & 3.14 & & Group2 & Ineffective & 2.49 \\
\hline \multirow{2}{*}{ stra 10} & Group1 & Effective & 2.96 & \multirow{2}{*}{ stra24 } & Group1 & Effective & 2.84 \\
\hline & Group2 & Ineffective & 2.89 & & Group2 & Ineffective & 2,52 \\
\hline \multirow{2}{*}{ stra11 } & Group1 & Effective & 2.88 & \multirow{2}{*}{ stra25 } & Group1 & Effective & 2.66 \\
\hline & Group2 & Ineffective & 2.65 & & Group2 & Ineffective & 2.41 \\
\hline \multirow{2}{*}{ stra12 } & Group1 & Effective & 2.78 & \multirow{2}{*}{ stra 26} & Group1 & Effective & 3.16 \\
\hline & Group2 & Ineffective & 2.54 & & Group2 & Ineffective & 2.84 \\
\hline \multirow{2}{*}{ stra 13} & Group1 & Effective & 2.98 & \multirow{2}{*}{ stra27 } & Group1 & Effective & 2.65 \\
\hline & Group2 & Ineffective & 2.79 & & Group2 & Ineffective & 3.08 \\
\hline \multirow{2}{*}{ stra14 } & Group1 & Effective & 3.21 & \multirow{2}{*}{ stra28 } & Group1 & Effective & 2.99 \\
\hline & Group2 & Ineffective & 2.77 & & Group2 & Ineffective & 2.89 \\
\hline
\end{tabular}


who divided the strategies into 3 categories each with several subdivisions.

Table 7. The top-down display of the most frequent use of listening strategy of effective listeners $(\mathrm{N}=15)$.

\begin{tabular}{|c|c|c|c|}
\hline RN & Strategy & Mean & ST \\
\hline \hline 1 & Stra13 & 3.21 & C \\
\hline 2 & Stra1 & 3.19 & M \\
\hline 3 & Stra 9 & 3.18 & M \\
\hline 4 & Stra26 & 3.16 & A \\
\hline 5 & Stra22 & 3.15 & C \\
\hline 6 & Stra 4 & 3.15 & M \\
\hline 7 & Stra16 & 3.14 & C \\
\hline 8 & Stra19 & 3.11 & C \\
\hline
\end{tabular}

$\mathrm{N}=$ Students Number; $\mathrm{ST}=$ Strategy Type; $\mathrm{RN}=$ Rank Number; $\mathrm{M}=$ Metacognitive strategy; $\mathrm{C}=$ Cognitive strategy; $\mathrm{A}=\mathrm{Affective} /$ Social strategy

Table 8. The top-down display of the most frequent use of listening strategy of ineffective listeners $(\mathrm{N}=15)$.

\begin{tabular}{|c|c|c|c|}
\hline RN & Strategy & Mean & ST \\
\hline \hline 1 & Stra9 & 3.14 & M \\
\hline 2 & Stra15 & 3.13 & C \\
\hline 3 & Stra19 & 3.11 & C \\
\hline 4 & Stra27 & 3.08 & A \\
\hline 5 & Stra18 & 3.06 & C \\
\hline
\end{tabular}

$\mathrm{N}=$ Students Number; $\mathrm{ST}=$ Strategy Type; $\mathrm{RN}=$ Rank Number; $\mathrm{M}=$ Metacognitive strategy; $\mathrm{C}=$ Cognitive strategy; $\mathrm{A}=$ Affective/Social strategy

According to Tables $\mathbf{7}$ and $\mathbf{8}$, we can see clearly the most frequent use of the 28-strategy items between effective and ineffective listeners.

Table 1 shows the 8 most often used strategies by effective listeners. They were selected out because their mean value is over 3.0. They were distributed to categories of 3 metacognitive strategies (listed in rank order including strategy1, planning, strategy9, summarization and strategy4, advance organizer); 4 cognitive strategies (listed in rank order including strategy13:guess; strategy22, inferencing and transfer; strategy 16: image and strategy9: paraphrase) and 1 affective/social strategy, strategy26:cooperation.

Table 3 displays the strategy used by ineffective listeners. That was also selected in the same way as effective listeners'. However, according to the principle that Mean> 3.0, only 5 strategies were effective, including one metacognitive strategy (strategy9, summarization); 3 cognitive strategies (strategy15, translation; strategy19, paraphrase and strategy18, remember.) and one affective/social strategy. (strategy27, encouragement.)
The two strategies that both listeners used frequently are 1 metacognitive strategy (strategy9: summarization) and 1 affective/social strategy (strategy19: repetition). However, from the Mean value in the Tables $\mathbf{1}$ and $\mathbf{2}$, it is easy to figure out there are varieties in degree.

\subsection{The Similarities and Differences Between Effective and Ineffective Listeners in Simultaneous Typing}

Considering about the 2 tables and descriptions, we know there really exist the same often used listening strategies between the two groups. Both groups employed strategy9, That is, I try to find out the reasons of ineffective listening. It's clear that both groups realized that efficient listening is a key point in listening comprehension. It's true that no listeners want inefficient listening. Another similarity is strategy 19, that is, I try to retell what I heard with my own words. This strategy is good for English learners, for they can improve their listening competence and at the same time improve their oral competence.

In this study, much more attention was paid to the differences between these two groups. Because differences can tell us why some are effective listeners while others are ineffective ones.

The tables above suggest that an extensive rang of listening strategies used more frequently by effective listeners than ineffective listeners. What's more, some of the strategies are really not efficient for listeners. For example, strategy18, I try to remember what I heard in English. It is known that it is impossible for the listeners to remember everything they heard in a listening task. And nowadays, with the instructions of the teachers and the development in cognition, many students begin to realize that one' memory capacity is quite limited and remembering isolated language items adds their memory burden and makes them miss the useful elements, so more and more students have accepted the opinion that comprehension greatly entails the listener's ability of chunking and ability of distinguish main points. As a result, it is assumed that they should pay more attention to some markers and clues that help them to solve the problem. At this point, the effective listeners did much better, nearly most of them have chosen strategy13, I guess the word I heard by its context and strategy 22, I do bold guesses on the context and associate them with the known knowledge according to the question. For the Affective/Social Strategy, the effective listeners chose strategy22, I often communicate with classmates and teachers to discuss the efficient ways of improving my listening. This strategy is very useful in study. A lot of scholars nowadays advocate cooperation in study. The students can communicate and cooperate with the peers, which can improve their study competence. The ineffective listeners chose strategy 27, I give myself a reward when I fulfill a listening. This is also good for study, however, encouragement is only the extrinsic to the learners, which cannot last for long.

The most obvious difference is the usage frequency between the two groups. The effective listeners employ more strategies than the effective listeners (Table 9). As O'Malley \& Chamot, Rubin and Lynch' [11] study indicates that strategies really do a lot in listening comprehension. 
Table 9. The same often used listening strategies between the two groups.

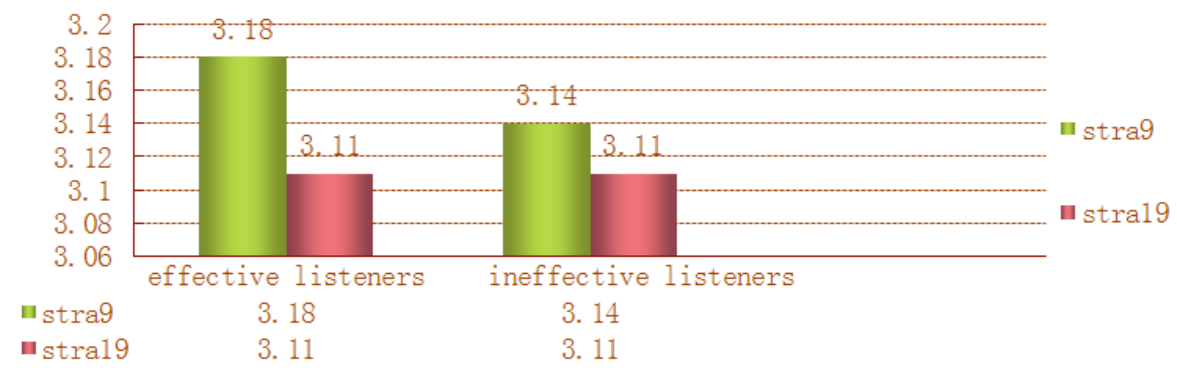

Table 10. Typing speed of the effective and ineffective listeners.

\begin{tabular}{|c|c|c|}
\hline $\begin{array}{c}\text { Typing Speed (Char- } \\
\text { acters Per Minute) }\end{array}$ & $\begin{array}{c}\text { The Total Number } \\
\text { of Ineffective Lis- } \\
\text { teners }\end{array}$ & $\begin{array}{c}\text { The Total Number } \\
\text { of Effective Listen- } \\
\text { ers }\end{array}$ \\
\hline \hline$\leq 90$ & 15 & 0 \\
\hline $90-119$ & 0 & 3 \\
\hline $120-149$ & 0 & 9 \\
\hline $150-179$ & 0 & 2 \\
\hline $180-209$ & 0 & 0 \\
\hline $210-239$ & 0 & 0 \\
\hline $240-269$ & 0 & 0 \\
\hline $270-299$ & 0 & 0 \\
\hline$\geq 300$ & 0 & $\mathbf{1 3 5}$ characters per \\
\hline minute
\end{tabular}

\subsection{Students' Typing Speed of the Effective and Ineffec- tive Listeners}

Table 10 shows the typing speed of effective and ineffective listeners respectively. From the Tables $\mathbf{5}$ and $\mathbf{6}$, we can see that for the ineffective listeners, their typing speed is low --- about 67 characters per minute. There is much room for these students to improve their typing speed through using some listening strategies since listening obstacle plays an important role in understanding the listening material, thus, influences their typing competence. Instead, the typing speed of the effective listeners is about 135 characters per minute, is much higher than that of the ineffective ones.

\section{SUGGESTIONS}

\subsection{Suggestions for EFL Instructors}

The significance is that it provides the English teachers with a more objective and better understanding of the students use and belief about their listening comprehension strategy so as to really draw up university students as a resource in instruction and maximize their chances of success in listening. Also English teachers should make an effort to analyze the reasons leading to comprehension breakdown and make counter measures to help students solve the problems. Meanwhile, English teachers should make strategy instruction a natural component of daily curriculum.

\subsection{Suggestions for Further Study}

The present study is focused on the LCSs use of a limited number of university students by examining the effective and ineffective listeners in simultaneous typing. In order to improve the reliability and validity of the experiment results, it is suggested that the studies take a larger size of sample, a better combination of proper assessment methods.

\section{CONFLICT OF INTEREST}

The authors confirm that this article content has no conflict of interest.

\section{ACKNOWLEDGEMENTS}

This work is supported by the Key Project of Wuchang Institute of Technology, China (No.2013JYZD06), "The Twelfth Five-year plan" project of Hubei Educational Science, China (No.2014B290).

\section{REFERENCES}

[1] L. Vandergrift, "The Comprehension strategies of second language (French) listeners: a descriptive study," Foreign Language Annual, vol. 30, no. 3, pp. 387-409, 1997.

[2] K. Perkins, "The teaching of listenning comprehension and communicative activities," TESOL Quarterly, vol. 131, no. 1, 1979.

[3] X. Huang, and M. Van Naerssen, "Learning strategies for oral communication," Applied Linguistics, vol. 8, pp. 287-307, 1985.

[4] J. Rubin, "the review of second language listening comprehension research," The Modern Language, vol. 78, no. 2, pp. 199-122, 1994

[5] J.M. O'Malley, A.U. Chamot, and L. Kupper, "Listening comprehension strategies in second language acquisition," Applied Linguistics, vol. 10, no. 4, pp. 418-437,1989.

[6] P.D. Pearson, and Dole, "Explicit comprehension instruction," Elementary School Journal, vol. 88, pp. 151-165,1987.

[7] J. Field, "Skills and strategies: towards a new methodology for listening," ELT Journal, vol. 52, no. 2, pp. 110-118, 1998.

[8] J.H. Flavell, "Metacognition and cognitive monitoring: A new area of cognitive development inquiry," American Psychologist, vol. 34, no. 10, pp. 906-911, 1979.

[9] L. Vandergrift, and M.H. Tafaghodtari, "Teaching L2 learners how to listen does make a difference: An empirical study," Language Learning, vol. 60, no. 2, pp. 490-497, 2010. 
[10] W. Wu, "Using learning strategies to develop listening comprehension: a case study," Teaching English in China, vol. 23, no. 1, pp. $42-45,2000$.
[11] A. Lynch, "Speaking up or talking down: Foreign learners' reactions to teacher talk," English Language Teaching, vol. 14, no. 2, pp. 109-116, 1988.

Received: June 10,2015

Revised: July 29, 2015

Accepted: August 15, 2015

(C) Zhou et al.; Licensee Bentham Open.

This is an open access article licensed under the terms of the (https://creativecommons.org/licenses/by/4.0/legalcode), which permits unrestricted, noncommercial use, distribution and reproduction in any medium, provided the work is properly cited. 